\title{
English for Academic Purpose: A Tool for Enhancing Students' Proficiency in English Language Skills
}

\author{
Emmanuel .C Sharndama ${ }^{1}$, Yakubu Samaila ${ }^{1} \&$ Yusuf Ishaya Tsojon ${ }^{1}$ \\ ${ }^{1}$ Federal Univesrity, Wukari \\ Correspondence: Emmanuel .C Sharndama(PhD), Faculty of Humanities,Management and Social Sciences, \\ Department of English and Literary Studies, Federal Univesrity, Wukari, Taraba State of Nigeria. E-mail: \\ esharndama@yahoo.com
}

Received: March 10, 2014 Accepted: April 22, $2014 \quad$ Online Published: April 28, 2014

doi:10.5430/ijelt.v1n2p14 URL: http://dx.doi.org/10.5430/ijelt.v1n2p14

\begin{abstract}
As the world today has become a global village with English as its primary language, the demand for English in different spheres of life is on the increase. The communicative role that English plays as the language of globalisation has resulted to its high demand in many spheres of human endeavours. In academia, many students are grossly deficient in English. Their deficiency cuts across the four Language skills (Listening, Speaking, Reading and Writing). This paper examined how English for Academic purposes can be utilized to enhance the students' proficiency in English Language skills. It was based on the theory and Practice of ESP. The paper established that EAP as a branch of English for Specific Purposes caters for the needs of students based on their academic disciplines or courses of study rather than general English. As EAP is not taught based on preordained methodology, different suggestions on how EAP could be used to improve the students' proficiency in English were made.
\end{abstract}

Keywords: ESP, EAP, Needs Analysis, Language Skills

\section{Introduction}

This study looks at the growing demand of English Language in today's Global Village with specific emphasis on academia. It sheds light on how English for academic purposes can enhance students' proficiency in English Language better than the numerous old approaches to the teaching of English Language. The demand for English Language all over the world is on the increase. This is because English Language plays different international roles. It is the language of globalisation, international politics and diplomacy, commerce, science and technology, computer and the internet among others. The increase in global interactions has stimulated the growing demand for proficiency in English language. Proficiency in academic context means effective and efficient use of English for communication and interaction with the print. The demand for proficiency in English in the academia is on the increase because most of the activities or works in institutions of learning in many countries of the world are done in English. As a result, some countries of the world today, teach English language as either a foreign or second language. In many English medium tertiary institutions, it is taught to beginning students in tertiary institutions to improve their proficiency and communicative competence to follow their academic courses of study successfully. The ability to understand and use language effectively to communicate in authentic social and school environment has for long been the aim of teaching English language to the beginning students in English medium speaking tertiary institutions.

Most of the methods adopted in teaching English were not geared towards achieving specific purpose nor tailored to the needs of the learners. Such methods range from Grammar Translation method; the direct method, the audio lingual method; the cognitive code method; situational language teaching, communicative language teaching among others (Nwogu\&Nwoke 2005). Problems of appropriate method or approach to the teaching of English have persisted for long. The quest for better method or approach by applied linguists to meet the growing demand for English in different fields of human endeavour has been ceaseless. In academia, EAP as a branch of ESP is one of the notable latest approaches to the teaching of English in higher institutions. In recent years, English for Academic Purposes (EAP) has become an expanding discipline within universities and other higher institutions. Afful (2007) describes EAP as literally located in English-medium universities and universities worldwide. Afful further states that in the USA, it is usually labelled Freshman Composition or General Composition and lately a variant called 
Writing in the Disciplines, it is often referred to as English for Academic Purposes (EAP) in the UK and Canada. Jordan (2002) in Afful (2007) states that EAP in the UK arose in response to the increasing internationalization of tertiary education, while Bazerman \& Russell,(1994) are of the view that Freshman's Composition and other allied programs in the USA arose as a response to the obvious decline in the quality of writing of students. Today, EAP is spreading fast as the result the demand for English in the world, especially in the academia.

According to Diane (2009), EAP is one of the types of ESP, tailored to the needs of the learners at various levels. Afful (2007) is of the view that a key course that is taught in many English-medium universities to facilitate the acquisition of academic literacy skills is English for Academic Purposes (EAP). This is because EAP is taught based on the needs or reasons for learning English. The teaching of EAP begins with the analysis of the students' linguistic background, what they have known and what they need to know. Diane (2009) citing Dudley-Evans \& St. John, 1998; Robinson, 1991, opines that this commitment to the purposes of the learners themselves is, to reiterate, what unites all the various branches of ESP. What the commitment entails is (1) first and foremost (before, during, and even after instruction),finding out what learners' needs are, then (2) developing or adapting materials and methods to enable needs-responsive instruction while concurrently(3) acquiring the expertise to function as needs-knowledgeable instructors.

As EAP is taught based on the needs of the students' of different programmes of study; the students' proficiency could be improved once their needs have been properly assessed. The EAP teacher designs syllabus and develop instructional materials based on the result of conducted needs analysis. The teaching of EAP in therefore is not based on specific preordained methodology but employs appropriate method based on the course content and the context of situation.

\section{Conceptual Theoretical Framework}

The study was based on the theory and practice of English for Specific Purposes (ESP).The concept of ESP has various definitions. According to Hutchinson and Waters (1987), ESP is an approach to Language Teaching in which all decisions as to the content and method are based on the learners' reason for learning. This means that it is a learner-centred approach to the teaching of English Language. The term ESP stands for English for Specific Purposes. It is a linguistic field of study that addresses the immediate and very specific needs of learners for a target language which is required for academic or professional purposes (Hossain 2013). Similarly, Richards and Schmidt (2010) in Mohammadi \& Mousavi 2013 describe English for Specific Purposes (ESP) as "a language course or program of instruction in which the content and aims of the course are fixed by the specific needs of a particular group of learners". Practically, speaking, ESP deals with preparing the Learners' to be able to use English in academic (students of different fields), professional (people of different professions such as doctors, engineers, and nurses), or workplace (technicians for example) settings. As it is about specific students, therefore, it must be tailored to the needs of these students.

ESP is also often defined in terms of communicative competence. McArthur (1996) for instance, describes ESP as a communicative based approach to the designing and teaching of English as against the traditional teaching of it as a second or foreign language. It is the English Language Teaching programme designed to meet the learners' needs in specific professional contexts. ESP is the English Language taught for professional, vocational and other specific purposes that originated in course of business English for foreign learners. It was developed in the 1960s in response to the demand for courses geared towards practical and functional rather than educational and cultural end. Planning ESP courses starts with needs analysis to establish the limits of the language that the learners need. According to Salto Youth, a needs analysis attempts to collect as much information as possible in order to build a comprehensive understanding of the needs and issues facing your NA. Once those needs are understood, it is a lot easier to identify potential solutions.

Focus on the learners' needs became as important as the method of teaching employed. These factors gave birth to the need for special language and method of teaching. Today the need for English at the local, national and international arenas cannot be over emphasized. The computer and the internet technologies have shrunken the world making it a global village. In academia, the demands for English seem to be more than other linguistic domain. English serves as medium of instruction in many institutions of learning in the world. EAP is a branch of EOP which is a branch of ESP associated professions. This branch of ESP is constantly expanding and generating off shoots such as English for Business Purposes(EBP),English for Legal Purposes,(ELP), English for Medical Purposes among others.EAP is taught in education domain to enable the students pursue their course studies effectively and efficiently. Like ESP itself, it is taught based on the needs of the learners or their reasons for learning English. The demand for 
English in academic and occupational settings led to the quest for better and appropriate methods of teaching. EAP rather than General English in institutions of learning today has revolutionalized the way English is taught. EAP programmes in most of the developed countries today are designed based on the needs of the students of particular disciplines. Hutchinson and Waters (1987) popular slogan 'tell me why you need English and I tell you the English you need' remains the guiding principles of designing and teaching EAP programmes in academic settings. It is against the above background that this paper examines how EAP approach enhances the students' proficiency in English better than other approaches.

\section{Literature Review}

\section{(a) English for Specific Purposes}

English for Specific Purposes (ESP) is a needs based concept to determine which language skills should be profitably developed for academic and professional success of the students. It takes into account certain basic questions like: "who the learners are, what their linguistic background or level of competence is, what their view to language learning is, what their purpose and expectations are, what particular skill they will be needing in their actual, on- thejob situation etc.

Thus, the ESP approach provides opportunities to the learners to acquire English naturally, by working with language in a context that they comprehend and find interesting (R.K.Singh 2005) English for Specific Purposes (ESP) is a generic name for all English teaching other than General English teaching. GateHouse (http://www.khae-service.com/) Opines that Carter (1983) identifies three types of ESP (i) English as a restricted language (ii) English for Academic and Occupational Purposes (iii) English with specific topics. In addition, Carter (1983) identifies the second type of ESP as English for Academic and Occupational Purposes. In the 'Tree of ELT' (Hutchinson \& Waters, 1987), ESP is broken down into three branches: a) English for Science and Technology (EST), b) English for Business and Economics (EBE), and c) English for Social Studies (ESS). Each of these subject areas is further divided into two branches: English for Academic Purposes (EAP) and English for Occupational Purposes (EOP). An example of EOP for the EST branch is 'English for Technicians' whereas an example of EAP for the EST branch is 'English for Medical Studies'. Hutchinson and Waters (1987) do note that there is not

English for Specific Purposes as an approach to English Language teaching has shifted focus away from the traditional structural treatments of language to discovering the ways in which language is used in real communication context. It is against this back ground that the learners' purpose of learning English determines the English to be taught. Some linguists began to support the view that the English needed by a particular group of learners could be identified by analyzing the linguistic characteristics of their specialist area of work or study (Hutchinson and Waters, 1987).

Learners were seen to have different needs and interests, which would have an important influence on their motivation to learn and, therefore, on the effectiveness of their learning. This lent support to the development of courses in which relevance to the learners' needs and interests was paramount. As a result, ESP was born (Hutchinson and Waters 1987 in Nodoushan 2007). As English became the accepted international language, it created a new generation of learners who knew specifically why they were learning it; time and money constraints created a need for cost effective courses with clearly defined goals.

\section{(b) English for Academic Purposes}

EAP as a branch of ESP is taught in higher institutions to improve the learners' proficiency in English Language and to help them to overcome some of their difficulties in English as a medium of instruction and communication. The first stage in the teaching of EAP is to assess why the students are learning English and the skills they need. This is what is called in the study of ESP needs analysis. Jarvis (2001) points out that in British Universities, English for academic purposes courses form an important language provision for non-native speakers(NNS).Jarvis also points out that EAP courses can be either pre -sectional, where students take the course before they go into further academic study or in-sessional, where students study while already on academic course. The pre-sessional EAP programme is designed to provide the learners of English as a foreign language with Basic English Language Skills that will enable them to pursue their academic course of study in English. The in-sectional on the other hand is taught to the learners of English as a second language to improve their proficiency in English.

Jarvis also made distinction between subject specific and common core EAP. The common core EAP focuses on general academic language skills, while the subject specific EAP looks at the language features of particular discipline. In common core EAP, students of different course backgrounds are taught the same language skills which 
may not have direct bearings on the students' academic course of study. The aims of teaching the two however is to equip the students with the language skills that will enable them follow their academic fields of study. Focus is made on the need to raise the students' English to enter higher institutions or study successfully.

\section{(c) What are Language Skills?}

Language facilitates learning more than any other thing. It is absolutely central to your learning; without it, understanding of the subject matter cannot be communicated or conveyed. For the instructor, it is a vehicle for transmitting or imparting knowledge, while for the learner it is a medium through which what has been transmitted is internalized. Students' academic English needs have to be developed in order for them to:

Understand and make the most effective use of their study materials.

Develop the specialised language and vocabulary relevant to their disciplines. Interpret assignment questions and select relevant and appropriate material for their response

(v) Communicate their needs to their tutors, and

(vi) Work productively and interact well with other students.

In order to use EAP to improve the students' proficiency in English Language skills, the tutor has to do need analysis to determine the learner's strengths and weakness. Needs analysis will also enable the tutor to design syllabus and develop materials relevant to their needs. If the above are done, the tutor has taken the first step towards utilizing EAP to improve the students' proficiency in English Language skills.

\section{Discussions}

The discussion of how EAP could be utilized to enhance the students' proficiency in English Language was done under subheadings. How to enhance students' proficiency in each of the Language skills were discussed using existing literature on English Language teaching. As EAP is not taught based on any pre-ordained methodology but on the learners' needs for English language in a particular context, the first step in teaching any EAP course is to find out why the students are learning English and what language skills they will need (Gillett 1996). This entails assessing the linguistic background of the learners to determine their abilities and what they need more. Iwai et al. (1999) in Songhori (2008) opines that the term needs analysis generally refers to the activities that are involved in collecting information that will serve as the basis for developing a curriculum that will meet the needs of a particular group of students. It is the process of finding out what the students already know, what they need to know and their interest. The knowledge of the students' needs will enable the teacher to design syllabus, develop materials and plan individual lessons. This implies that the content of the syllabus or lesson to be taught as well as materials to be used are determined by the needs of the learners.

\section{(a) Teaching Grammatical Structures}

Equipping the learners with needed language skills to successfully pursue their academic course of study is the overall goal of Teaching English for Academic purposes. It is one of the approaches to English language teaching that is purposeful and communicative. To achieve this goal, EAP teachers need to work towards enhancing the students' Language skills. Enhancing the students' language skills depends to a large extent on their knowledge of grammatical structures. This is because grammar cuts across all aspects of communication in academic setting. In order to enhance the students' proficiency in English through the teaching of EAP, the EAP teacher ought to carry out needs analysis to determine the grammatical structures that needs to be taught instead of teaching every grammatical structure as in general English class. The grammatical structures to be taught therefore could be discipline specific or topical. Discipline or subject specific grammatical structures as identified through needs analysis should be taught. Needs analysis will enable the teacher to identify the grammatical structures that the students know already and those that they need to know. The teacher based on the knowledge and the students' abilities engages them in modelling of the sentences and in specified context. The EAP teacher after identifying the ability of the students should develop materials and decide on the appropriate method. Whichever method is chosen, the students' purpose of learning should be of paramount importance. In utilizing the EAP programme to improve the students' knowledge of grammatical structures, the steps of grammar teaching in Pekoz (2008), could be utilized. Pekoz opines that grammar teaching should involve pre-, while- and post-stages in an attempt to provide integrated learning environments. In the pre-grammar stage, the teacher should bring grammar instruction to life, stimulate 
interest in the topic, and raise awareness by providing a reason for learning. The while-grammar stage should facilitate noticing of the new grammar point, and provide meaningful input through contextual examples, pictures, and texts. Finally, the post-grammar stage should provide an opportunity to put grammar to use, and relate grammar instruction to real life situations. The main distinction between the while- and post-stages is that the while-stage involves the clarification of the meaning, whereas the post-stage focuses on the productive aspects of the new structure. In the EAP class, developed materials based on the learners' needs are to be used. The application of the identified grammatical structures should be taught and the students should as well be engaged in exercies.

\section{(b) Enhancing Academic Writing skills}

This is the most essential content of EAP courses in most tertiary institutions. It includes all forms of writing peculiar to tertiary educational settings. Academic writing is undertaken more frequently than any other activity in academic settings. It ranges from everyday academic writing such as taking lecture notes or doing written class works to more complex writing tasks that the learners engage in as part of the fulfilments for the award of certificates in their course of studies. Such tasks may include laboratory reports, and investigative reports like term papers, thesis and dissertations. These writing tasks have conventions that the students are expected to adhere to strictly. Academic writing requires critical skills, such as the selection of topics, organisation of ideas in clauses, paragraphs and the global text. The EAP teacher is charged with the responsibility of training the students to acquire these skills. The EAP teacher for instance may display topics on the wall from which the students could make selection. Similarly, the general structures such as the background, statement of problems/thesis statement, objectives, research questions, results and discussions could be pasted on the wall for students. The teacher may group the students to work on selected topics under group leaders, while he/she serves as facilitator.

Academic writing according to Gillett (1996) prepares students for academic writing tasks. These tasks vary very much from writing short answers in exams to writing dissertations and theses. Of course, accurate grammar, punctuation and language use forms an important component of an EAP writing class, along with specific teaching of the formal language required. This will involve the teaching of the different text types, linking words, signposting expressions, introductions and conclusions.

In order to improve the learners' writing in EAP class, the teacher should make the lesson task or project based. The teacher may group the students and engage them in different tasks. Each group should be instructed to select a topic, narrow the topic, generate and organise ideas, develop them and draw conclusion. For more tedious tasks such as report writing, thesis and dissertations, all the conventions should be made familiar to the learners. The learners should be taught how to conduct research using the library or the internet and taking note. Today, websites are very crucial sources from where teachers and learners can draw materials relevant to writing tasks. The learners in this case should be exposed to language teaching websites and be guided on how to utilise them.

Writing involves some processes or stages. In order to enhance the students' communicative competence via the medium of writing, the EAP practitioner should teach them the process of writing. The writing process or stages that the students should be exposed to in order to communicate well in writing include:

(i) Selecting a topic

(ii) Brainstorming or generating ideas (thinking and jotting everything about the topic

(iii) Planning/outlining (organizing the generated ideas in sequence or chronological order )

(iv) Writing the first draft (developing the outlined ideas.

(v) Reading and editing the draft.

(vi) Rewriting the draft( Writing the second draft)

(vii) Proof reading (Reading and making the final editing).

The above writing process is common in writing tasks such as essay and letter writing. The learners should be exposed to the types of essay and letter their differing conventions and linguistic features. The learners should also be exposed to advanced academic writing tasks such as laboratory reports, projects and dissertations which may require advanced and complex skills. Advance academic writing combines mastery of the conventions and linguistic features. These require research and practice to explore the topic under investigation.

\section{(c) Enhancing Academic Listening Skills}

Listening skill in EAP is an amalgam of listening and language problems. It is assumed that the learners have acquired preliminary listening skills in general English courses taught at the primary and secondary school levels. 
The EAP teachers in tertiary institutions are to expose the students to advanced listening skills such as listening to lectures and taking lecture note, and discriminating between points worth taking and those not worth taking. This means that the students should be taught how to sieve the grain from the chaff. In addition to listening, the students should be made familiar with the following as forming the content of EAP listening skills: recognising linking words or discourse markers, deducing the meaning of strange words, noting and selecting essential information, and summarising key ideas in lectures. The learners should be engaged in some listening tasks such as listening and writing a phrase or sentence dictated by the lecturer or Paraphrasing ideas. In order to improve the students' proficiency in listening, the EAP teacher is should first assess the students' listening abilities as well as their problems. He develops materials relevant to the needs and adopts appropriate contextual methods.

\section{(d) Enhancing Reading Skills}

Students from English medium schools may not have serious problems with the basic reading skills in EAP course. The EAP Teacher at tertiary level is supposed to pay much attention on advanced reading skills. Students are to be exposed to the structure of texts in addition to general reading skills which include scanning (reading to find relevant part of text) or skimming (reading to get the gist. They should be taught the strategies of locating key terms or concepts as well as deducing meanings of words and structures of sentences, the functions of discourse markers and cohesive devices, distinguishing between major and minor ideas, and efficient reading (surveying the text, chapter/article, paragraphs, skimming for gist/general impression scanning to locate specifically required information reading quickly). Above all, the SQ3R method of reading which crucial in advanced reading should be explaine (Survey, question, Reading, Recite and Review).Relevant materials could be developed to illustrate the application of the SQ3R strategy.

\section{Conclusion}

This paper has looked at the emergence of English for Specific Purposes as an approach to the teaching of English language based on the learner's reason for learning. It has also established the fact that EAP is a branch of ESP. EAP is taught based on the students' academic needs for English. The approach could improve students' proficiency as the content, the materials and the methods are based on the assessed language needs of the students. In spite of the different labels in different countries, the common goals of teaching EAP is to improve the students' proficiency in English in order to help them pursue their academic course of studies. The paper has focused on Common core EAP as being language skill based. Suggestions as to how to enhance the students' Language skills through the teaching of EAP have been provided. The paper for instance provided suggestions on how to enhance students' communicative competence through contextual teaching of grammatical structures, listening skills, reading and writing. They are mere suggestions because EAP is not taught based on pre-ordained methodology. The students' needs and reasons for learning English determine the materials and methods. EAP teaching therefore is founded on needs analysis or assessment.

\section{References}

Afful, J. B. (2007). Academic Literacy and Communicative Skills in the Ghanaian University: A Proposal. Nebula 4(3), September 2007.

Bayram, P. (2008). Integrating Grammar for Communicative Language Teaching. The Internet TESL Journal. Retrieved on 31st March, 2014 from http://iteslj.org/Techniques/Pekoz-Grammar.html

Diane, B. (2009). English for Specific Purposes in Theory and Practice: What ESP Is and Can Be: An Introduction. Retrieved from http://www.press.umich.edu/titleDetailDesc.do?id=770237 Michigan ELT, 2009.

E-merging blogs. (2011). Teaching English:ESP (EOP and EAP) Discussion Group. The Internet TESL Journal, Vol. XIV.

Gillett, A. J. (1996). What is EAP? - Using English for Academic. Retrieved from http://www.uefap.com/articles/eap.htm

Hossain, Md. J. (2013). ESP Needs Analysis for Engineering Students: A Learner Centered Approach. Journal of PU, Part: B Vol.2, No.2, PRESIDENCY UNIVERSITY.

Hutchinson T., \& Waters A. (1987). English for Specific Purposes. Cambridge, Cambridge University Press.

Jarvis, H. (2001). Internet usage of English for Academic Purposes courses. Cambridge, Cambridge, University Press. 
K. Singh. (2005). Teaching English for Specific Purposes: An Evolving Experience. Kristen Gatehouse: Key Issues in English for Specific Purposes (ESP) Curriculum Development. The Internet TESL Journal. Retrieved from http://www.khae-service.com/; http://iteslj.org/Techniques/Pekoz-Grammar.html

McArthur, T. (1996). Oxford Companion to the English Language. Oxford, Oxford University.

Mehdi, H. S. (2008). Introduction to Needs Analysis.English for Specific Purposes world issue, 4. Retrieved from www.esp.world

Nondoushan M. A. S. (2007). Are Task Type and familiarizing predicators of performance on test of Language for Specific Purposes. The Asian ESP Journal, 3(1). Retrieved 31st March, 2014 from http://www.asian-esp-journal.com/index.php/journal-index/subject-index/106-language-for-specific-purposes-ab ility

Nwogu K. N., \& Nwoke A. (2005). A Hand Book on the Teaching of English Language in Secondary Schools. Jos, MonoExpressions LTD (2005).

Vali M., \& Mousavi N. (2013). Analyzing Needs Analysis in ESP: A (re) modeling. International Research Journal of Applied and Basic Sciences, 4(5), 1014-1020. Science Explorer Publications.

What is needs analysis? Retrieved on $30^{\text {th }}$ March, 2014 from https://www.salto 